Article

\title{
Motility, Biofilm Formation and Antimicrobial Efflux of Sessile and Planktonic Cells of Achromobacter xylosoxidans
}

\author{
Signe M. Nielsen ${ }^{1,2}$, Line N. Penstoft ${ }^{2}$ and Niels Nørskov-Lauritsen ${ }^{2, *}$ (C) \\ 1 Department of Clinical Medicine, Health, Aarhus University, DK-8200 Aarhus, Denmark; sinnel@rm.dk \\ 2 Department of Clinical Microbiology, Aarhus University Hospital, DK-8200 Aarhus, Denmark; \\ Line@thearmypainter.com \\ * Correspondence: nielnoer@rm.dk; Tel.: +45-7856-5603
}

Received: 19 December 2018; Accepted: 24 January 2019; Published: 27 January 2019

check for updates

\begin{abstract}
Achromobacter xylosoxidans is an innately multidrug-resistant bacterium capable of forming biofilms in the respiratory tract of cystic fibrosis (CF) patients. During the transition from the planktonic stage to biofilm growth, bacteria undergo a transcriptionally regulated differentiation. An isolate of A. xylosoxidans cultured from the sputum of a CF patient was separated into sessile and planktonic stages in vitro, and the transcriptomes were compared. The selected genes of interest were subsequently inactivated, and flagellar motility was found to be decisive for biofilm formation in vitro. The spectrum of a new resistance-nodulation-cell division (RND)-type multidrug efflux pump (AxyEF-OprN) was characterized by inactivation of the membrane fusion protein. AxyEF-OprN is capable of extruding some fluoroquinolones (levofloxacin and ciprofloxacin), tetracyclines (doxycycline and tigecycline) and carpabenems (ertapenem and imipenem), which are classes of antimicrobials that are widely used for treatment of CF pulmonary infections.
\end{abstract}

Keywords: Achromobacter xylosoxidans; cystic fibrosis; transcriptomics; biofilm; antimicrobial efflux

\section{Introduction}

Achromobacter species are emerging pathogens in cystic fibrosis (CF) [1-3]. Antimicrobial treatment of Achromobacter is challenging due to innate and acquired resistance towards a wide range of antimicrobial agents [4-7]; moreover, these bacteria have the capacity for biofilm formation [8-10], which is critical for antimicrobial tolerance. The transition from planktonic to sessile growth is an environmentally driven process induced by external factors [11]. The characteristics of bacterial cells embedded in biofilms include the lack of motility, excretion of extracellular matrix components, increased activity of efflux pumps and altered metabolic processes [11-15]. The achievable back-transition to the planktonic phase indicates that sessile growth is regulated by temporary, reversible alterations, rather than persistent mutations in the genome [11,16,17].

The gene expression profile of Pseudomonas aeruginosa during planktonic growth differed from the expression in in vitro biofilms subjected to experimental stress $[17,18]$. We have previously characterized the progression of gene regulation from early to late isolates cultured from a single patient chronically infected with Achromobacter xylosoxidans [19]. In the present study, we perform the transcriptomic analysis of a single isolate cultured during biofilm and planktonic growth phases in vitro. Noticeable differences are further characterized by the assessment of biofilm formation and the antimicrobial susceptibility of knockout mutants. 


\section{Results and Discussion}

\subsection{Differentially Expressed Genes}

AX08 was propagated at sessile and early stationary planktonic growth phases in vitro. The strain is the "intermediate isolate" (CF-2b) that was used to characterize Achromobacter biofilm morphology [10] and gene expression [19]. Transcriptomic analysis during the separate conditions revealed a total of 232 differentially expressed genes, using a five-fold limit for significant difference. Annotation by RAST (Rapid Annotation using Subsystem Technology) [20] suggested that 89 genes encode hypothetical proteins, while 143 proteins of known or presumed functions were distributed into 16 subsystem categories; of these, 104 were upregulated and 39 were downregulated during sessile growth. The full list of 143 differentially regulated genes is presented in Table S1; selected genes and regulatory adjustments are shown in Table 1.

Table 1. Selected regulatory adjustments during sessile growth.

\begin{tabular}{|c|c|c|c|}
\hline \multirow{2}{*}{$\begin{array}{l}\text { Gene Name } \\
\text { RND efflux system membrane fusion protein } A x y A\end{array}$} & \multirow{2}{*}{$\begin{array}{l}\text { Function } \\
\text { Virulence }\end{array}$} & \multicolumn{2}{|c|}{ Fold Change } \\
\hline & & $\mathrm{Up}$ & 7.4 \\
\hline Flagellar basal-body rod modification protein FlgD & Flagellar motility & Down & -7.3 \\
\hline Flagellar basal-body rod protein $F \operatorname{lgC}$ & Flagellar motility & Down & -5.1 \\
\hline Flagellar biosynthesis protein $F \operatorname{lhB}$ & Flagellar motility & Down & -5.1 \\
\hline Flagellar biosynthesis protein FliC & Flagellar motility & Down & -8.5 \\
\hline Flagellar biosynthesis protein FliL & Flagellar motility & Down & -6.7 \\
\hline Flagellar biosynthesis protein FliQ & Flagellar motility & Down & -5.2 \\
\hline Flagellar biosynthesis protein FliT & Flagellar motility & Down & -5.2 \\
\hline Flagellar hook-associated protein $\mathrm{Flg} K$ & Flagellar motility & Down & -5.2 \\
\hline Flagellar hook-associated protein $F \lg L$ & Flagellar motility & Down & -5.3 \\
\hline Flagellar hook-associated protein FliD & Flagellar motility & Down & -6.0 \\
\hline Flagellar hook-basal body complex protein FliE & Flagellar motility & Down & -5.4 \\
\hline Flagellar L-ring protein $\mathrm{FlgH}$ & Flagellar motility & Down & -5.0 \\
\hline Flagellar motor switch protein FliM & Flagellar motility & Down & -5.7 \\
\hline Flagellar motor switch protein FliN & Flagellar motility & Down & -7.3 \\
\hline Flagellar M-ring protein FliF a & Flagellar motility & Down & -6.3 \\
\hline Flagellar protein FliJ & Flagellar motility & Down & -5.9 \\
\hline Universal stress protein family (tandem domain) & Stress response & Down & $-9.2,-6.1$ \\
\hline Universal stress protein $U s p A$ & Stress response & Down & -6.6 \\
\hline Diguanylate cyclase/ phosphodiesterase & Stress response & Up & 11.4 \\
\hline Cystathionine beta-lyase, MetC ${ }^{a}$ & Methionine biosynthesis & $\mathrm{Up}$ & 86 \\
\hline Exopolysaccharide biosynthesis glycosyltransferase, EpsF & EPS biosynthesis & $\mathrm{Up}$ & 6.4 \\
\hline ATP-binding proteins, KpsT, KpsE, KpsM & Cell wall and capsule & $\mathrm{Up}$ & 5.1 to 8.7 \\
\hline
\end{tabular}

${ }^{\text {a }}$ Selected for gene inactivation.

\subsubsection{Increased Efflux Pump Activity During Sessile Growth}

Efflux pumps are key mechanisms of resistance in Gram-negative bacteria, and many bacterial species harbor several RND-type multi-drug resistance pumps [21-24]. Four operons encoding RND (resistance-nodulation-division)-type multidrug efflux pumps designated MexAB-OprM, MexCD-OprJ, MexEF-OprN and MexXY-OprM have overlapping but different substrate specificities in P. aeruginosa [25]. Annotation of Achromobacter strain AX08 by RAST revealed the presence of similar operons in this species (not shown). Bador et al. demonstrated the involvement of AxyAB-OprM in A. xylosoxidans (with homology to MexAB-OprM) in resistance to cephalosporins (except cefepime), aztreonam, nalidixic acid, fluoroquinolones and chloramphenicol [26], whereas AxyXY-OprZ (with homology to MexXY-OprM) is responsible for the intrinsic high-level resistance of A. xylosoxidans to aminoglycosides [27]. When we compared the efflux pumps of successive isolates cultured at various time-points after the initial colonization, only AxyAB-OprM was significantly upregulated [19]. In P. aeruginosa, this efflux pump is characterized by the broadest-spectrum activity [25]. We compared gene regulation of a single isolate separated into planktonic or sessile growth phases, and observed a 7.4 times upregulation of axyA during sessile growth (Table 1). Thus, 
this efflux pump may be involved in Achromobacter biofilm metabolism, in addition to antimicrobial tolerance. Bacterial efflux pumps are not restricted to the extrusion of antimicrobial agents but can dispose solutes, metabolites, quorum sensing molecules and toxins [28-30]. The axyB gene of the AxyAB-OprM operon, also encoding the axyA gene found to be upregulated in AX08 biofilm, was successfully inactivated Achromobacter by Bador et al. [26]. Therefore, we decided to investigate another, yet uncharacterized, RND efflux pump of Achromobacter strain AX08 sharing closest similarity with MexEF-OprN of P. aeruginosa.

The efflux pump of Achromobacter is designated AxyEF-OprN, and axyE was selected for inactivation.

\subsubsection{Motility, Stress Response and Quorum Sensing}

All 16 differentially expressed genes encoding flagellar motility were downregulated during biofilm growth (range: -8.5 to -5 , Table 1 ). Stress response genes were generally upregulated in sessile AX08, but genes of the universal stress protein family (usp $A$ and a tandem domain) were downregulated (Table 1 and Table S1). For E. coli, inactivation of the universal stress proteins, UspC and UspE, abrogate motility [31]; the decreased expression of the usp genes in A. xylosoxidans during sessile growth suggests a similar involvement in this species. We observed an increased expression of the diguanylate cyclase/phosphodiesterase gene in sessile AX08 (Table 1). Cyclic-di-GMP acts as a quorum sensing secondary messenger in Pseudomonas aeruginosa, and elevated levels of cyclic-di-GMP, mediated by diguanylate cyclases and phosphodiesterases, are associated with decreased motility and formation of biofilm in that species [32,33]. The mechanisms of Achromobacter quorum sensing has not been examined, but our data suggest involvement of cyclic-di-GMP in the biofilm growth phase of A. xylosoxidans, possibly in quorum sensing signalling.

The flagellar M-ring protein, FliF (Table 1), is required for the synthesis of a functional flagellum [34], and fliF was selected for inactivation.

\subsubsection{Sulfur Metabolism}

The most pronounced upregulation during sessile growth ( 86 fold) occurred in the cystathionine beta-lyase (metC) gene (Table 1). Anaerobic conditions occur in sputum from chronically infected CF patients, and Achromobacter can grow anaerobically by denitrification $[35,36]$. The high upregulation could indicate a role for sulfur metabolism during anaerobic growth of Achromobacter in vivo, with organic or non-organic sulfur components acting as electron acceptors. Furthermore, sulfur is required for the bacterial production of methionine. Sulfur is assimilated by the sulfate pathway, where sulfite oxidase oxidizes sulfite to sulfate, which is incorporated into cysteine. Cysteine functions as a sulfur donor in methionine biosynthesis, catalyzed by cystathionine beta-lyase (MetC) [37], and the metC gene has been shown to be of importance to the virulence of Salmonella enterica serovar Typhimurium $[38,39]$.

Although anaerobic conditions are unlikely to prevail in a three-day-old biofilm, an increased expression of met $C$ could potentially be a response to the decreased levels of oxygen and nutrients in the inner parts of the in vitro-grown biofilm. In our previous analysis of sequential isolates of the present strain isolated during a time-span of seven years [19], a putative sulfite oxidase gene was progressively upregulated, suggesting a role of the sulfate pathway for adaptation to long-term colonization.

met $C$ was selected for inactivation.

\subsubsection{Constituents of the Extracellular Matrix}

Exopolysaccharides are important constituents of the extracellular matrix [14,40]. Gene expression in biofilm showed an increase in genes affecting the formation and maintenance of the cell wall and capsule, and contributing to the formation of the extracellular matrix. Expression of the epsF gene, encoding exopolysaccharide biosynthesis, increased 6.4 times during sessile growth (Table 1), and the capsular polysaccharide $\mathrm{ABC}$ transporters, KpsT, KpsE and KpsM, increased 5.1 to 8.7 times during 
sessile growth (Table 1). The ABC transporter complex (KpsT/KpsM) exports polysaccharides across the cytoplasmic membrane [41] and, thereby, contributes to the increased generation of extracellular matrix components of Achromobacter biofilm.

Overproduction of alginate induces the mucoid phenotype and is a hallmark of chronic infection with P. aeruginosa, [42]. The alginate biosynthesis protein, AlgJ, is present in the genome of AX08. However, no increase in expression of this gene occurred during sessile growth, and alginate may not be an essential part in the generation of Achromobacter biofilm.

\subsection{Examination of Inactivated Mutants}

The investigation of the relevance of motility, cellular discharge and methionine biosynthesis for biofilm formation and antimicrobial susceptibility took place by the construction of knockout mutants $(\triangle f l i F, \triangle a x y E$ and $\triangle m e t C$, respectively), and inactivation of the selected genes were confirmed by whole-genome sequencing (not shown).

\subsubsection{RND-Type Efflux Pump AxyEF-OprN Affects Antimicrobial Susceptibility and Biofilm} Formation

A two-fold or larger decrease in the minimal inhibitory concentration (MIC) was observed for selected agents of three antimicrobial classes, namely, carbapenems, flouroquinolones and tetracyclines (Table 2); with respect to levofloxacin, the MIC was reduced below the interpretative criterion defined by EUCAST for Pseudomonas spp. ( $\leq 1 \mathrm{mg} / \mathrm{L},[43]$ ), rendering the isolate susceptible to this agent. Unexpected increases in MIC were observed for the $\beta$-lactam antimicrobial agents, ceftazidime (2-fold) and doripenem (4-fold), which belong to the cephalosporin- and carbapenem-class of $\beta$-lactams, respectively (Table 2); this opposite effect was reproduced in three independent experiments.

Table 2. The minimal inhibitory concentrations (MICs) of AX08 and $\triangle \mathrm{axyE}$.

\begin{tabular}{ccccc}
\hline & \multicolumn{2}{c}{ AX08 Wildtype } & \multicolumn{2}{c}{ AX08 $\Delta$ axyE } \\
\hline Antibiotic $(\mu \mathrm{g} / \mathrm{mL})$ & MIC & S/R & MIC & S/R \\
\hline Colistin & 1 & $\mathrm{~S}$ & 1 & $\mathrm{~S}$ \\
Polymyxin B & 1 & $\mathrm{NI}$ & 1 & $\mathrm{NI}$ \\
Piperacillin & 8 & $\mathrm{~S}$ & 8 & $\mathrm{~S}$ \\
Ticarcillin/Clavulanic Acid & $\leq 16$ & $\mathrm{~S}$ & $\leq 16$ & $\mathrm{~S}$ \\
Cefepime & 8 & $\mathrm{~S}$ & 8 & $\mathrm{~S}$ \\
Cefotaxime & $>32$ & $\mathrm{R}$ & $>32$ & $\mathrm{R}$ \\
Ceftazidime & 4 & $\mathrm{~S}$ & 8 & $\mathrm{~S}$ \\
Aztreonam & $>16$ & $\mathrm{R}$ & $>16$ & $\mathrm{R}$ \\
Ertapenem & 1 & $\mathrm{NI}$ & 0.5 & $\mathrm{NI}$ \\
Doripenem & 0.25 & $\mathrm{~S}$ & 1 & $\mathrm{~S}$ \\
Imipenem & 2 & $\mathrm{~S}$ & $\leq 1$ & $\mathrm{~S}$ \\
Meropenem & $\leq 1$ & $\mathrm{~S}$ & $\leq 1$ & $\mathrm{~S}$ \\
Ciprofloxacin & 2 & $\mathrm{R}$ & 1 & $\mathrm{R}$ \\
Levofloxacin & 2 & $\mathrm{R}$ & $\leq 1$ & $\mathrm{~S}$ \\
Amikacin & $>32$ & $\mathrm{R}$ & $>32$ & $\mathrm{R}$ \\
Gentamicin & $>8$ & $\mathrm{R}$ & $>8$ & $\mathrm{R}$ \\
Tobramycin & $>8$ & $\mathrm{R}$ & $>8$ & $\mathrm{R}$ \\
Doxycycline & 8 & $\mathrm{NI}$ & 4 & $\mathrm{NI}$ \\
Minocycline & $\leq 2$ & $\mathrm{NI}$ & $\leq 2$ & $\mathrm{NI}$ \\
Tigecycline & 0.5 & $\mathrm{NI}$ & $\leq 0.25$ & $\mathrm{NI}$ \\
Trimethoprim/ Sulfamethoxazole & $\leq 0.5$ & $\mathrm{NI}$ & $\leq 0.5$ & $\mathrm{NI}$ \\
\hline
\end{tabular}

* Interpretation of susceptibility according to EUCAST clinical MIC breakpoints for Pseudomonas spp. S: Sensitive, R: Resistant, NI: No Interpretation.

Thus, the AxyEF-OprN efflux pump may be involved in the innate antimicrobial resistance of A. xylosoxidans. The extrusion of antimicrobials was limited compared with the broader spectrum 
targeted by AxyXY-OprZ, and particularly AxyAB-OprM [20,21]. A narrow substrate specificity spectrum also characterizes the MexEF-OprN efflux pump of P. aeruginosa, which exhibits the narrowest spectrum of the RND efflux pumps of that species [30]. Further studies are needed to elucidate the biological role of AxyEF-OprN in A. xylosoxidans.

A clinical isolate of $A$. xylosoxidans resistant to meropenem with increased levels of a novel betalactamase with carpabanemase activity, Axc, and an amino acid substitution at position 29 of the axyZ gene (V29G) suggests that axc expression is regulated by AxyZ [44]. The putative TetR family transcriptional regulator, encoded by the axyZ gene, functions as a negative regulator of the AxyXY-OprZ efflux pump. The exposure to tobramycin in strains with this particular mutation led to the overproduction of the AxyXY-OprZ efflux pump, resulting in increased MIC towards a range of antimicrobials including aminoglycosides, fluoroquinolones and tetracyclines [45]. The mechanisms of acquired resistance in Achromobacter may have implications for treatment strategies, warranting further investigation of Achromobacter resistance mechanisms.

The $\triangle A x y E$ mutant was characterized by a slight decrease in biofilm formation (16\%) measured as adherence to, and subsequent growth on, abiotic surfaces (Figure 1). However, this insubstantial decrease is not considered clinically relevant and no visual difference in biofilm morphology was demonstrated (Figure 2).

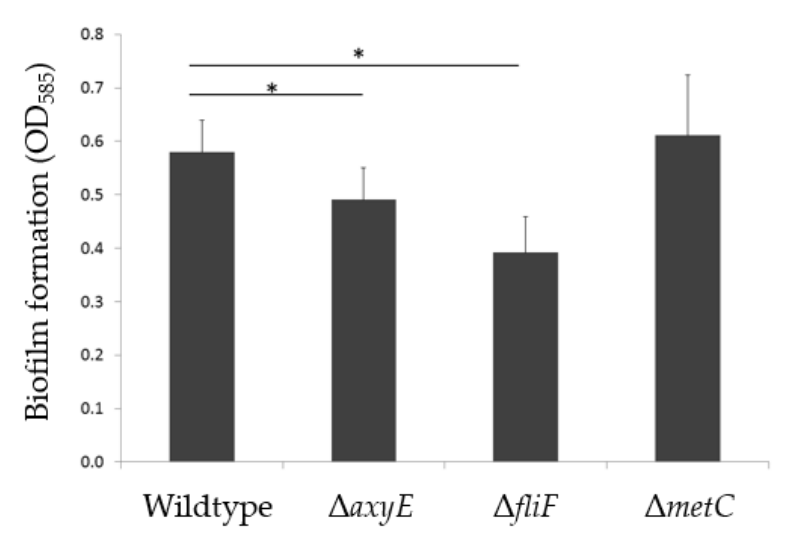

Figure 1. Mean production of biofilm in A. xylosoxidans AX08 and knockout mutants of the RND efflux system $(\triangle a x y E)$, flagellar M-ring protein $(\triangle f l i F)$ and methionine biosynthesis $(\Delta m e t C)$.

The relatively undisturbed formation of biofilm is in accordance with previous results showing no effect of the general efflux pump inhibitor, phenylalanine arginyl $\beta$-naphthylamide, on A. xylosoxidans biofilm formation [19]. Since inactivation of axyE reduced the MIC of levofloxacin, rendering the mutant sensitive to this compound, the effect on antimicrobial susceptibility towards levofloxacin in biofilm was likewise tested. However, no reduction in the minimal biofilm eradication concentration (MBEC) was observed (not shown).

\subsubsection{Motility Impairment Affects Biofilm Formation}

The non-motile character of sessile growth was reflected by the downregulation of all genes involved in flagellar motility (Table 1 and Table S1). However, flagellar motility is required for the inception of the biofilm [33]. Inactivation of the flagellar M-ring protein, FliF, resulted in a $39 \%$ reduction of in vitro biofilm formation on peg-lids (Figure 1), and visualization by confocal laser scanning microscopy (CLSM) demonstrated an almost complete lack of biofilm formation (Figure 2). The importance of flagellar motility for biofilm formation has been demonstrated in other bacterial species including $P$. aeruginosa $[33,46,47]$. Whether flagellar motility affects the formation of Achromobacter aggregates in CF sputum, in vivo, remains to be studied. 


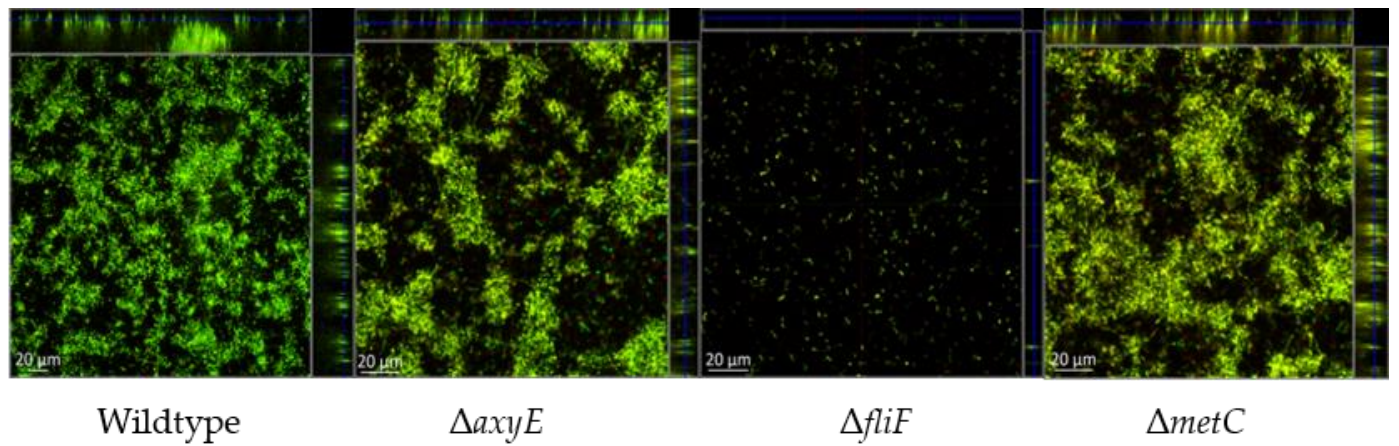

Figure 2. Visualization by confocal laser scanning microscopy (CLSM) of static biofilms in wildtype $A$. xylosoxidans AX08 and knockout mutants of the RND efflux system ( $\triangle a x y E)$, flagellar M-ring protein $(\triangle f l i F)$ and methionine biosynthesis $(\triangle m e t C)$. Representative images from three biological replicates.

\subsubsection{Methionine Biosynthesis}

Methionine biosynthesis depends on the assimilation of sulfur by the sulfate pathway, where cysteine functions as a sulfur donor in methionine biosynthesis, catalyzed by cystathionine beta-lyase (MetC) [37]. Due to the hyperexpression of this gene during sessile growth, we speculated that MetC, besides playing a putative role in anaerobic respiration, might be important for the establishment of Achromobacter biofilm. Cysteine is a precursor of methionine, and inactivation of CymR, the master regulator of cysteine metabolism in S. aureus, plays a role in biofilm formation in this species [48]. However, inactivation of the metC gene ( $\Delta$ metC) in AX08 did not affect the amount or morphology of biofilm on abiotic surfaces (Figures 1 and 2), or the planktonic growth rate (Supplementary Figure S1). Possibly, the nutrient-rich Brain Heart Infusion (BHI) growth media could have masked potential effects, and the putative role of MetC in Achromobacter biofilm formation is unresolved. Additional experiments using a minimal growth media and anoxic biofilm growth conditions are required to further clarify the role of MetC in Achromobacter biofilm.

In conclusion, we characterized an additional RND efflux pump in A.xylosoxidans designated AxyEF-OprN. Despite a relatively narrow spectrum of extrusion of antimicrobial agents, deletion of the linker protein of this pump rendered the isolate susceptible to levofloxacin. The disruption of flagellar motility caused an almost complete nullification of biofilm formation. Transcriptomic analysis highlighted several subsystems and genes of importance for sessile growth in A. xylosoxidans.

\section{Materials and Methods}

\subsection{Clinical Strain of A. xylosoxidans}

The strain designated AX08 corresponds to the "intermediate isolate" of Achromobacter xylosoxidans cultured 1 year after initial colonization [19]. This isolate was characterized by a pronounced adherence to abiotic surfaces (also designated isolate CF2-b in [10]). The isolate was routinely cultured on $5 \%$ blood agar at $37^{\circ} \mathrm{C}$.

\subsection{Culture at Separate Growth Phases and RNA Extraction}

Planktonic cultures were generated by overnight incubation with shaking at $180 \mathrm{rpm}$ of a single colony transferred to $10 \mathrm{ml}$ of $\mathrm{BHI}$ media. The early stationary growth phase was prepared by the dilution of overnight cultures to an $\mathrm{OD}_{600}$ of 0.1 (corresponding to approximately $10^{6}$ cells $/ \mathrm{mL}$ ) and the transfer of $1 \mathrm{~mL}$ to Erlenmeyer flasks containing $10 \mathrm{ml}$ of BHI media in triplicate. The cultures were grown with shaking at $180 \mathrm{rpm}$ to an $\mathrm{OD}_{600 \mathrm{~nm}}$ of 0.8 , which corresponds to the early stationary growth phase (Figure S1), and then stabilized by treatment with RNA Protect (RNeasy Protect Bacteria Mini Kit, Qiagen, Hilden, Germany) according to the manufacturer's recommendations. The preparation of biofilms in six-well plates and the extraction of RNA were performed as described [19]. 
RNA was purified using the RNeasy Protect Bacteria Mini Kit (Qiagen) according to the manufacturer's protocol for enzymatic lysis and the proteinase $\mathrm{K}$ digestion of bacteria, with the lysis time extended to 30 minutes. The samples were treated twice with RNAprotect for 15 minutes. Turbo DNase (Ambion) treatment was used to degrade DNA. The integrity of the RNA samples was evaluated by Qubit ${ }^{\text {TM }}$ Fluorometric Quantitation (Thermo-Fisher Scientific, Waltham, MA, USA) and treated with Ribo-Zero ${ }^{\mathrm{TM}}$ rRNA Removal Kit (Bacteria) (Illumina, San Diego, CA, USA) to remove rRNA prior to sequencing

\subsection{Sequencing and Data Processing}

The cDNA preparation, sequencing and data processing of mRNA extracted from separate growth phases were performed as previously described [19], using ScriptSeq ${ }^{\mathrm{TM}}$ Complete Kit (Bacteria)-Low Input (Illumina), the Illumina NextSeq 500 platform generating $150 \mathrm{bp}$ long paired-end reads, and the CLC Genomics Workbench RNAseq tools (https:/ / www.qiagenbioinformatics.com/).

\subsection{Gene Inactivation}

The pUC19 vector is incapable of replication in Achromobacter [26] and was used as a suicide vector. pUC19 encodes a carboxy-penicillinase, and strain AX08 is innately susceptible to ticarcillin. The primers for PCR were designed to amplify approximately $800 \mathrm{bp}$ of the genes, and included 15 bases of homology with the ends of the linearized pUC19 vector (Table 3).

The plasmids were constructed using the In Fusion ${ }^{\circledR}$ HD cloning kit (Clonetech Laboratories, Inc. USA) and transformed into competent Escherichia coli Stellar ${ }^{\mathrm{TM}}$ cells according to the manufacturer's protocols. The transformants were selected on LB plates containing $50 \mu \mathrm{g} / \mathrm{mL}$ of ticarcillin. The plasmids were purified using a Plasmid Purification Midi kit (Qiagen).

AX08 cells were cultured overnight in $\mathrm{BHI}$ to an $\mathrm{OD}_{600 \mathrm{~nm}}$ of between 1 and 1.5. Forty milliliter cultures were transferred to a $50 \mathrm{~mL}$ Falcon tube and cooled on ice for 20 minutes. For the generation of electro-competence, the cells were pelleted by centrifugation at $3500 \mathrm{rpm}$ for 10 minutes at $4{ }^{\circ} \mathrm{C}$, resuspended in $40 \mathrm{~mL}$ of $0.3 \mathrm{M}$ sucrose and centrifuged again for at $3500 \mathrm{rpm}$ for 10 minutes at $4{ }^{\circ} \mathrm{C}$. After being washed in sucrose buffer three times, the cells were resuspended in $400 \mu \mathrm{L}$ of sucrose buffer and placed on ice for 1-2 hours.

Table 3. Primers used for the generation of knockout mutants.

\begin{tabular}{llcl}
\hline Primer & Nucleotide Sequence $\left(5^{\prime}-\mathbf{3}^{\prime}\right)$ & Fragment Length $(\mathbf{b p})$ & Target Gene \\
\hline FliF_F & CGGTACCCGGGGATCGAACAGATCAACTACCAGCG & 771 & Flagellar M-ring gene, fliF \\
FliF_R & CGACTCTAGAGGATCTTGATGTGGCTGATGGTG & 795 & $\begin{array}{l}\text { RND-type multidrug resistance efflux } \\
\text { pump gene, axyE }\end{array}$ \\
AxyE_F & CGGTACCCGGGGATCGACGTCAAGGAAAACCAG & \multirow{2}{*}{ Cystathionine beta-lyase gene, metC } \\
AxyE_R & CGACTCTAGAGGATCGGGCAACTGTTCGATCTT & & \\
MetC_F & CGGTACCCGGGGATCTGATGCAGGACAAGGAGT & & \\
MetC_R & CGACTCTAGAGGATCTAGGCGTAGGTGTCGTAG & & \\
M14Fa & CCAGGGTTTCCCAGTCACGA & & \\
M14R & GCGGATAACAATTTCACACAGGA & & \\
\hline
\end{tabular}

Underlined sequences comprise 15 bases of homology with the ends of the linearized vector pUC19. ${ }^{a}$ M14F and M14R primers are located in the vector adjacent to the insertion site.

The plasmids were introduced by electroporation. Sixty milliliters of electro-competent AX08 and five microliters of plasmid (1-5 $\mu \mathrm{g}$ DNA) were mixed in an Eppendorf tube and left on ice for ten minutes. The suspension was transferred to an ice cold 1-mm electroporation cuvette (Cuvettes Plus $^{\mathrm{TM}}$ Electroporation Cuvettes, BTX ${ }^{\mathrm{TM}}$, VWR, Radnor, Pennsylvania, USA) and electroporated using a Bio Rad MicroPulser ${ }^{\mathrm{TM}}$ (Bio Rad, Hercules, CA, USA) at $1.5 \mathrm{kV}$ for approximately $5 \mathrm{~ms}$. Immediately thereafter, one milliliter of pre-heated $\left(37^{\circ} \mathrm{C}\right) \mathrm{LB}$ media was added to the cuvette and gently mixed with the bacterial suspension. The mixture was transferred to an Eppendorf tube and incubated for two hours at $37^{\circ} \mathrm{C}$ with shaking at $120 \mathrm{rpm}$. The recombinant bacteria were selected by plating $200 \mu \mathrm{L}$ on LB agar plates containing $50 \mu \mathrm{g} / \mathrm{mL}$ of ticarcillin. The remaining $800 \mu \mathrm{L}$ of bacterial suspension was centrifuged at $6000 \mathrm{rpm}$ for five minutes. The supernatant was removed and the pellet 
was resuspended in $200 \mu \mathrm{L}$ of growth media and plated on LB agar plates containing $50 \mu \mathrm{g} / \mathrm{mL}$ of ticarcillin. The plates were incubated for two days at $37^{\circ} \mathrm{C}$. The insertion of the target gene into the pUC19 vector was confirmed by the amplifying target sequences of the insert and the vector, and the insertion of the plasmid into the target gene was verified using whole-genome sequencing of the mutants. The libraries for whole-genome sequencing were prepared from $1 \mathrm{ng}$ gDNA using Nextera XT (Illumina) and were subsequently sequenced on a NextSeq 500 ( $2 \times 150$ bp, Illumina).

\subsection{Visualization and Quantitation of Biofilm Formation}

The overnight cultures in $\mathrm{BHI}$ broth were adjusted to an $\mathrm{OD}_{600 \mathrm{~nm}}$ of 0.1 , and $180 \mu \mathrm{L}$ were transferred in triplicate to wells in a 96-well plate with a glass bottom constructed for confocal microscopy (Ibidi $\mu$-Plate 96 well, Ibidi, GmbH, Martinsried, Germany). The plates were incubated for 72 hours at $37^{\circ} \mathrm{C} ; 100 \mu \mathrm{L}$ of BHI was carefully replaced with fresh broth in each well after 24 and $48 \mathrm{~h}$ avoiding agitation of the biofilm developing at the bottom. The biofilms were stained with LIVE/DEAD®stain (BacLight 27007 bacterial viability kit for microscopy, Invitrogen, Thermo Fisher, Waltham, MA USA) according to the manufacturer's protocol, except that an increased concentration of propidium iodide $(0.05 \mathrm{mM})$ was used for the staining of extracellular DNA [49]. The biofilms were imaged by confocal laser scanning microscopy (CLSM) (Zeiss LSM 700, Carl Zeiss AG, Oberkochen, Germany). The biofilm formation was quantified using the crystal violet microtiter assay, modified and adapted for adherence to peg-lids [50,51], as previously described [10].

\subsection{Antimicrobial Susceptibility}

The minimal inhibitory concentration (MIC) was determined for 21 antimicrobial agents using Sensititre GNX2F plates incubated for $20 \mathrm{~h}$ at $37{ }^{\circ} \mathrm{C}$ and analyzed by the Sensititre ${ }^{\circledR}$ Windows Software SWIN®(Termo-Fischer Scientific, Waltham, MA, USA) according to the manufacturer's recommendations. The minimal biofilm eradication concentration (MBEC) of levofloxacin was determined as described previously [10].

Supplementary Materials: The following are available online at http:/ / www.mdpi.com/2076-0817/8/1/14/ s1: Figure S1: Growth curves of AX08 (wildtype) and knockout mutants, $\triangle m e t C, \triangle a x y E$ and $\Delta f l i F p ;$ Table S1: Differentially expressed genes.

Author Contributions: S.M.N. and N.N.-L. conceived and designed the experiments; S.M.N. performed the experiments and analyzed the data; L.N.P. contributed with the experimental procedure for gene inactivation; S.M.N. and N.N.-L. wrote the paper, N.N.-L. edited and revised the paper.

Acknowledgments: Julian Bador and Catherine Neuwirth are thanked for helpful suggestions regarding gene inactivation of Achromobacter. Financial support to N.N.L. was obtained from the Lundbeck Foundation (Grant R146-2012-12145).

Conflicts of Interest: The authors declare no conflict of interest. The founding sponsors had no role in the design of the study; in the collection, analyses, or interpretation of data; in the writing of the manuscript, and in the decision to publish the results.

\section{References}

1. Davies, J.C.; Rubin, B.K. Emerging and unusual gram-negative infections in cystic fibrosis. Semin. Respir. Crit. Care Med. 2007, 28, 312-321. [CrossRef] [PubMed]

2. De Baets, F.; Schelstraete, P.; Van Daele, S.; Haerynck, F.; Vaneechoutte, M. Achromobacter xylosoxidans in cystic fibrosis: Prevalence and clinical relevance. J. Cyst. Fibros. 2007, 6, 75-78. [CrossRef] [PubMed]

3. Dupont, C.; Michon, A.L.; Jumas-Bilak, E.; Norskov-Lauritsen, N.; Chiron, R.; Marchandin, H. Intrapatient diversity of Achromobacter spp. involved in chronic colonization of Cystic Fibrosis airways. Infect. Genet. Evol. 2015, 32, 214-223. [CrossRef] [PubMed]

4. Rolston, K.V.; Messer, M. The in-vitro susceptibility of Alcaligenes denitrificans subsp. xylosoxidans to 40 antimicrobial agents. J. Antimicrob. Chemother. 1990, 26, 857-860. [CrossRef]

5. Raso, T.; Bianco, O.; Grosso, B.; Zucca, M.; Savoia, D. Achromobacter xylosoxidans respiratory tract infections in cystic fibrosis patients. Eur. J. Clin. Microbiol. Infect. Dis. 2008, 116, 837-841. 
6. Almuzara, M.; Limansky, A.; Ballerini, V.; Galanternik, L.; Famiglietti, A.; Vay, C. In vitro susceptibility of Achromobacter spp. isolates: Comparison of disk diffusion, Etest and agar dilution methods. Int. J. Antimicrob. Agents 2010, 35, 68-71. [CrossRef] [PubMed]

7. Amoureux, L.; Bador, J.; Siebor, E.; Taillefumier, N.; Fanton, A.; Neuwirth, C. Epidemiology and resistance of Achromobacter xylosoxidans from cystic fibrosis patients in Dijon, Burgundy: First French data. J. Cyst. Fibros. 2013, 12, 170-176. [CrossRef] [PubMed]

8. Hansen, C.R.; Pressler, T.; Nielsen, K.G.; Jensen, P.O.; Bjarnsholt, T.; Hoiby, N. Inflammation in Achromobacter xylosoxidans infected cystic fibrosis patients. J. Cyst. Fibros. 2010, 9, 51-58. [CrossRef]

9. Jakobsen, T.H.; Hansen, M.A.; Jensen, P.O.; Hansen, L.; Riber, L.; Cockburn, A.; Kolpen, M.; Ronne Hansen, C.; Ridderberg, W.; Eickhardt, S.; et al. Complete genome sequence of the cystic fibrosis pathogen Achromobacter xylosoxidans NH44784-1996 complies with important pathogenic phenotypes. PLoS ONE 2013, 8, e68484. [CrossRef]

10. Nielsen, S.M.; Norskov-Lauritsen, N.; Bjarnsholt, T.; Meyer, R.L. Achromobacter Species Isolated from Cystic Fibrosis Patients Reveal Distinctly Different Biofilm Morphotypes. Microorganisms 2016, 4, 33. [CrossRef]

11. De la Fuente-Nunez, C.; Reffuveille, F.; Fernandez, L.; Hancock, R.E. Bacterial biofilm development as a multicellular adaptation: Antibiotic resistance and new therapeutic strategies. Curr. Opin. Microbiol. 2013, 16, 580-589. [CrossRef] [PubMed]

12. Hall-Stoodley, L.; Costerton, J.W.; Stoodley, P. Bacterial biofilms: From the natural environment to infectious diseases. Nat. Rev. Microbiol. 2004, 2, 95-108. [CrossRef] [PubMed]

13. Costerton, J.W.; Stewart, P.S.; Greenberg, E.P. Bacterial biofilms: A common cause of persistent infections. Science 1999, 284, 1318-1322. [CrossRef] [PubMed]

14. Flemming, H.C.; Wingender, J. The biofilm matrix. Nat. Rev. Microbiol. 2010, 8, 623-633. [CrossRef] [PubMed]

15. Stoodley, P.; Sauer, K.; Davies, D.G.; Costerton, J.W. Biofilms as complex differentiated communities. Annu. Rev. Microbiol. 2002, 56, 187-209. [CrossRef] [PubMed]

16. McDougald, D.; Rice, S.A.; Barraud, N.; Steinberg, P.D.; Kjelleberg, S. Should we stay or should we go: Mechanisms and ecological consequences for biofilm dispersal. Nat. Rev. Microbiol. 2011, 10, 39-50. [CrossRef] [PubMed]

17. Dotsch, A.; Eckweiler, D.; Schniederjans, M.; Zimmermann, A.; Jensen, V.; Scharfe, M.; Geffers, R.; Haussler, S. The Pseudomonas aeruginosa transcriptome in planktonic cultures and static biofilms using RNA sequencing. PLoS ONE 2012, 7, e31092. [CrossRef]

18. Dingemans, J.; Monsieurs, P.; Yu, S.H.; Crabbe, A.; Forstner, K.U.; Malfroot, A.; Cornelis, P.; Van Houdt, R. Effect of Shear Stress on Pseudomonas aeruginosa Isolated from the Cystic Fibrosis Lung. MBio 2016, 7. [CrossRef]

19. Nielsen, S.; Meyer, R.; Nørskov-Lauritsen, N. Differences in gene expression profiles between early and late isolates in monospecies Achromobacter biofilm. Pathogens 2017, 6, 20. [CrossRef]

20. Aziz, R.K.; Bartels, D.; Best, A.A.; DeJongh, M.; Disz, T.; Edwards, R.A.; Formsma, K.; Gerdes, S.; Glass, E.M.; Kubal, M.; et al. The RAST Server: Rapid annotations using subsystems technology. BMC Genom. 2008, 9, 75. [CrossRef]

21. Van Acker, H.; Coenye, T. The Role of Efflux and Physiological Adaptation in Biofilm Tolerance and Resistance. J. Biol. Chem. 2016, 291, 12565-12572. [CrossRef] [PubMed]

22. Baugh, S.; Ekanayaka, A.S.; Piddock, L.J.; Webber, M.A. Loss of or inhibition of all multidrug resistance efflux pumps of Salmonella enterica serovar Typhimurium results in impaired ability to form a biofilm. J. Antimicrob. Chemother. 2012, 67, 2409-2417. [CrossRef] [PubMed]

23. Lamers, R.P.; Cavallari, J.F.; Burrows, L.L. The efflux inhibitor phenylalanine-arginine beta-naphthylamide (PAbetaN) permeabilizes the outer membrane of gram-negative bacteria. PLoS ONE 2013, 8, e60666. [CrossRef] [PubMed]

24. Kvist, M.; Hancock, V.; Klemm, P. Inactivation0 of efflux pumps abolishes bacterial biofilm formation. Appl. Environ. Microbiol. 2008, 74, 7376-7382. [CrossRef] [PubMed]

25. Aeschlimann, J.R. The role of multidrug efflux pumps in the antibiotic resistance of Pseudomonas aeruginosa and other gram-negative bacteria. Insights from the Society of Infectious Diseases Pharmacists. Pharmacotherapy 2003, 23, 916-924. [CrossRef] [PubMed] 
26. Bador, J.; Amoureux, L.; Duez, J.M.; Drabowicz, A.; Siebor, E.; Llanes, C.; Neuwirth, C. First description of an RND-type multidrug efflux pump in Achromobacter xylosoxidans, AxyABM. Antimicrob. Agents Chemother. 2011, 55, 4912-4914. [CrossRef] [PubMed]

27. Bador, J.; Amoureux, L.; Blanc, E.; Neuwirth, C. Innate aminoglycoside resistance of Achromobacter xylosoxidans is due to AxyXY-OprZ, an RND-type multidrug efflux pump. Antimicrob. Agents Chemother. 2013, 57, 603-605. [CrossRef]

28. Li, X.Z.; Nikaido, H. Efflux-mediated drug resistance in bacteria: An update. Drugs 2009, 69, $1555-1623$. [CrossRef]

29. Schroeder, M.; Brooks, B.D.; Brooks, A.E. The Complex Relationship between Virulence and Antibiotic Resistance. Genes 2017, 8, 39. [CrossRef]

30. Soto, S.M. Role of efflux pumps in the antibiotic resistance of bacteria embedded in a biofilm. Virulence 2013, 4, 223-229. [CrossRef]

31. Nachin, L.; Nannmark, U.; Nystrom, T. Differential roles of the universal stress proteins of Escherichia coli in oxidative stress resistance, adhesion, and motility. J. Bacteriol. 2005, 187, 6265-6272. [CrossRef] [PubMed]

32. Valentini, M.; Filloux, A. Biofilms and Cyclic di-GMP (c-di-GMP) Signaling: Lessons from Pseudomonas aeruginosa and Other Bacteria. J. Biol. Chem. 2016, 291, 12547-12555. [CrossRef] [PubMed]

33. Ha, D.G.; O'Toole, G.A. c-di-GMP and its Effects on Biofilm Formation and Dispersion: A Pseudomonas Aeruginosa Review. Microbiol. Spectr. 2015, 3. MB-0003-2014. [CrossRef]

34. Bergeron, J.R. Structural modeling of the flagellum MS ring protein FliF reveals similarities to the type III secretion system and sporulation complex. PeerJ 2016, 4, 1718. [CrossRef] [PubMed]

35. Kolpen, M.; Hansen, C.R.; Bjarnsholt, T.; Moser, C.; Christensen, L.D.; van Gennip, M.; Ciofu, O.; Mandsberg, L.; Kharazmi, A.; Döring, G.; et al. Polymorphonuclear leucocytes consume oxygen in sputum from chronic Pseudomonas aeruginosa pneumonia in cystic fibrosis. Thorax 2010, 65, 57-62. [CrossRef] [PubMed]

36. Kolpen, M.; Kragh, K.N.; Bjarnsholt, T.; Line, L.; Hansen, C.R.; Dalbøge, C.S.; Hansen, N.; Kühl, M.; Høiby, N.; Jensen, P.Ø. Denitrification by cystic fibrosis pathogens-Stenotrophomonas maltophilia is dormant in sputum. Int. J. Med. Microbiol. 2015, 305, 1-10. [CrossRef]

37. Clausen, T.; Huber, R.; Prade, L.; Wahl, M.C.; Messerschmidt, A. Crystal structure of Escherichia coli cystathionine gamma-synthase at 1.5 A resolution. EMBO J. 1998, 17, 6827-6838. [CrossRef]

38. Ejim, L.J.; D'Costa, V.M.; Elowe, N.H.; Loredo-Osti, J.C.; Malo, D.; Wright, G.D. Cystathionine beta-lyase is important for virulence of Salmonella enterica serovar Typhimurium. Infect. Immun. 2004, 72, 3310-3314. [CrossRef]

39. Shah, D.H.; Shringi, S.; Desai, A.R.; Heo, E.J.; Park, J.H.; Chae, J.S. Effect of metC mutation on Salmonella Gallinarum virulence and invasiveness in 1-day-old White Leghorn chickens. Vet. Microbiol. 2007, 119, 352-357. [CrossRef]

40. Mayer, C.; Moritz, R.; Kirschner, C.; Borchard, W.; Maibaum, R.; Wingender, J.; Flemming, H.C. The role of intermolecular interactions: Studies on model systems for bacterial biofilms. Int. J. Biol. Macromol. 1999, 26, 3-16. [CrossRef]

41. Whitfield, C. Biosynthesis and assembly of capsular polysaccharides in Escherichia coli. Annu. Rev. Biochem. 2006, 75, 39-68. [CrossRef] [PubMed]

42. Hentzer, M.; Teitzel, G.M.; Balzer, G.J.; Heydorn, A.; Molin, S.; Givskov, M.; Parsek, M.R. Alginate overproduction affects Pseudomonas aeruginosa biofilm structure and function. J. Bacteriol. 2001, 183, 5395-5401. [CrossRef] [PubMed]

43. The European Committee on Antimicrobial Susceptibility Testing_EUCAST. Available online: http://www. eucast.org/clinical_breakpoints / (accessed on 9 March 2018).

44. Fleurbaaij, F.; Henneman, A.A.; Corver, J.; Knetsch, C.W.; Smits, W.K.; Nauta, S.T.; Giera, M.; Dragan, I.; Kumar, N.; Lawley, T.D.; et al. Proteomic identification of Axc, a novel beta-lactamase with carbapenemase activity in a meropenem-resistant clinical isolate of Achromobacter xylosoxidans. Nat. Sci. Rep. 2018, 8, 8181. [CrossRef] [PubMed]

45. Bador, J.; Neuwirth, C.; Grangier, N.; Muniz, M.; Germé, L.; Bonnet, J.; Pillay, V.; Llanes, C.; de Curraize, C.; Amoureux, L. Role of AxyZ transcriptional regulator in overproduction of AxyXY OprZ multidrug efflux system in Achromobacter species mutants selected by tobramycin. Antimicrob. Agents Chemother. 2017, 61, 8. [CrossRef] [PubMed] 
46. Whiteley, M.; Bangera, M.G.; Bumgarner, R.E.; Parsek, M.R.; Teitzel, G.M.; Lory, S.; Greenberg, E.P. Gene expression in Pseudomonas aeruginosa biofilms. Nature 2001, 413, 860-864. [CrossRef]

47. Guttenplan, S.B.; Kearns, D.B. Regulation of flagellar motility during biofilm formation. FEMS Microbiol. Rev. 2013, 37, 849-871. [CrossRef] [PubMed]

48. Soutourina, O.; Poupel, O.; Coppee, J.Y.; Danchin, A.; Msadek, T.; Martin-Verstraete, I. CymR, the master regulator of cysteine metabolism in Staphylococcus aureus, controls host sulphur source utilization and plays a role in biofilm formation. Mol. Microbiol. 2009, 73, 194-211. [CrossRef] [PubMed]

49. Allesen-Holm, M.; Barken, K.B.; Yang, L.; Klausen, M.; Webb, J.S.; Kjelleberg, S.; Molin, S.; Givskov, M.; Tolker-Nielsen, T. A characterization of DNA release in Pseudomonas aeruginosa cultures and biofilms. Mol. Microbiol. 2006, 59, 1114-1128. [CrossRef] [PubMed]

50. O'Toole, G.A. Microtiter dish biofilm formation assay. J. Vis. Exp. 2011, 47, 2437. [CrossRef]

51. Harrison, J.J.; Stremick, C.A.; Turner, R.J.; Allan, N.D.; Olson, M.E.; Ceri, H. Microtiter susceptibility testing of microbes growing on peg lids: A miniaturized biofilm model for high-throughput screening. Nat. Protoc. 2010, 5, 1236-1254. [CrossRef]

(C) 2019 by the authors. Licensee MDPI, Basel, Switzerland. This article is an open access article distributed under the terms and conditions of the Creative Commons Attribution (CC BY) license (http:/ / creativecommons.org/licenses/by/4.0/). 